\section{(2) \\ BRAZIULIAN JOURNAL \\ OF MEDICAL AND BIOLOGICAL RESEARCH}

www.bjournal.com.br
ISSN 0100-879X

Volume 45 (7) 565-680

July 2012

CLINICAL INVESTIGATION

Braz J Med Biol Res, July 2012, Volume 45(7) 591-600

doi: 10.1590/S0100-879X2012007500059

Percent body fat is a better predictor of cardiovascular risk factors than body mass index

Qiang Zeng, Sheng-Yong Dong, Xiao-Nan Sun, Jing Xie and Yi Cui

The Brazilian Journal of Medical and Biological Research is partially financed by

\section{욛NPq}

Ministério

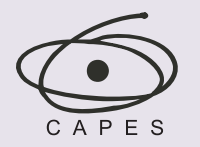

Ministério da Educação

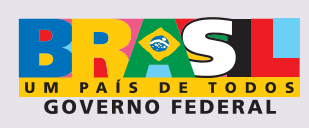

DTFAPESP

Institutional Sponsors

Ф SHIMADZU

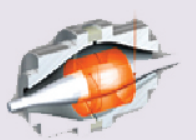

М디맘

Associaçäo
Fundo

Explore High - Performance MS Orbitrap Technology

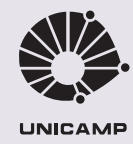
analitice Thermo 


\title{
Percent body fat is a better predictor of cardiovascular risk factors than body mass index
}

\author{
Qiang Zeng*, Sheng-Yong Dong*, Xiao-Nan Sun, Jing Xie and Yi Cui \\ International Medical Center, Chinese PLA General Hospital, Beijing, China
}

\begin{abstract}
The objective of the present study was to evaluate the predictive values of percent body fat (PBF) and body mass index (BMI) for cardiovascular risk factors, especially when PBF and BMI are conflicting. BMI was calculated by the standard formula and PBF was determined by bioelectrical impedance analysis. A total of 3859 ambulatory adult Han Chinese subjects (2173 males and 1686 females, age range: 18-85 years) without a history of cardiovascular diseases were recruited from February to September 2009. Based on BMI and PBF, they were classified into group 1 (normal BMI and PBF, N = 1961), group 2 (normal BMI, but abnormal PBF, $\mathrm{N}=381$ ), group 3 (abnormal BMI, but normal PBF, $\mathrm{N}=681$ ), and group 4 (abnormal $\mathrm{BMI}$ and PBF, $\mathrm{N}=836$ ). When age, gender, lifestyle, and family history of obesity were adjusted, PBF, but not BMI, was correlated with blood glucose and lipid levels. The odds ratio (OR) and 95\% confidence interval $(\mathrm{Cl})$ for cardiovascular risk factors in groups 2 and 4 were $1.88(1.45-2.45)$ and $2.06(1.26-3.35)$ times those in group 1, respectively, but remained unchanged in group 3 (OR = 1.32, $95 \% \mathrm{Cl}=0.92-1.89$ ). Logistic regression models also demonstrated that PBF, rather than BMI, was independently associated with cardiovascular risk factors. In conclusion, PBF, and not BMI, is independently associated with cardiovascular risk factors, indicating that PBF is a better predictor.
\end{abstract}

Key words: Obesity; Body composition; Body mass index; Cardiovascular disease; Risk factor; Percent body fat; Bioelectrical impedance

\section{Introduction}

Obesity, a metabolic disorder characterized by the accumulation of excessive body fat, is closely associated with metabolic derangement-related diseases, and may also lead to cardiovascular diseases, diabetes, and joint problems. The prevalence of obesity is increasing rapidly in the world, exacting a heavy toll both socially and economically. In the United States, recent trends in obesity indicate that the prevalence of obesity or overweight among 20- to 74 -year-old adults increased to almost $66 \%$ from 1980 to 2004 , and it has been estimated that obesity accounts for 5 to $15 \%$ of total annual deaths $(1,2)$. In China, more than one third of the adults are overweight or obese, and 10 to $20 \%$ of the adult population has diseases related to metabolic disorders (3). Stewart et al. (4) have warned that if we fail to address continued increases in obesity, we may risk eroding the pattern of steady gains in health, which we have achieved since the early 20th century.

Accurate determination of body fat could provide clinically useful guidance for physicians to assess disease risks in patients with obesity and optimize preventive or therapeutic remedies for these patients (5). Measurement of body fat has been traditionally limited to simple measures, such as waist circumference, waist-to-hip ratio and body mass index (BMI). Due to its ease of measurement and calculation, $\mathrm{BMI}$ is the most widely used diagnostic tool to identify weight problems within a population. Previous studies have shown that increased BMI is associated with an increased risk of metabolic derangement-related diseases and may be used as an indicator for the prediction of these diseases (6). However, because of the inability of BMI to discriminate between body fat and lean mass, its diagnostic performance in intermediate ranges of body weight

Correspondence: Qiang Zeng, International Medical Center, Chinese PLA General Hospital, 28 Fuxing Road, Beijing 100853, China. E-mail: zq301@hotmail.com

*These authors contributed equally to this study.

Received October 3, 2011. Accepted April 9, 2012. Available online April 20, 2012. Published July 2, 2012. 
is limited; it cannot accurately categorize individuals who have a normal body weight with too much body fat but too little muscle and those who have an excessive body weight with too little body fat but too much muscle $(7,8)$. Recently, a meta-analysis of 32 different samples comprising a total of 31,968 patients revealed that the commonly used BMI cutoff values to diagnose obesity fail to identify half of the people with excess percent body fat (PBF) (9).

Although BMI appears to be a good indicator of the deposition of excess energy as fat in adult white men and women in Europe and North America, several studies suggest that BMI is less appropriate for Asian populations who differ in body build and body proportions $(10,11)$, a fact that could result in misclassification because of the different contributions of bone mass, muscle mass, and fluid to body weight. In a recent study, it was demonstrated that the currently recommended BMI cutoff scores to define overweight and obesity overestimated overweight and obesity prevalence in African-American men and women, and underestimated prevalence in Asian-Indian men and women, Asian women and Hispanic women, indicating a racial/ethnic bias of the universal overweight and obesity BMI cutoff scores (8). Therefore, it is necessary to develop and redefine appropriate country-specific and ethnicityspecific BMI cutoff values and assess the validity and utility of other measures such as PBF, in order to facilitate the development of preventive and therapeutic strategies to minimize the health risks resulting from obesity.

PBF is defined as the proportion of individual fat mass over body weight. Previous studies have shown that PBF more accurately reflects body composition than BMI, although both BMI and PBF have been used for the evaluation of human health risks such as cardiovascular risk in clinical practice $(12,13)$. A higher PBF and/or BMI often indicates a higher level of cardiovascular risk (14). However, the relationship between PBF and $\mathrm{BMI}$ is not linear $(15,16)$. A high PBF does not necessarily mean a high BMI, and vice versa. Thus, there is a need to accurately determine the cardiovascular risk in individuals who have a normal PBF but a high BMI or a high PBF but a normal BMI. In other words, whether BMI or PBF more accurately predicts cardiovascular risk factors needs to be evaluated.

Since the 1990s, a bioelectrical impedance technique has been widely used to measure the content of different tissues noninvasively, based on their differences in electric conductivity and it may provide an index of total body water, from which the fat-free mass and PBF can be derived (17). Using this technique, we previously demonstrated that PBF better reflected cardiac function and arterial compliance than other currently used indices such as BMI (18).

In the present study, we determined the correlations of $\mathrm{BMI}$ and PBF with cardiovascular risk factors such as hypertension, dyslipidemia and hyperglycemia by measuring the body composition of 3859 subjects using the bioelectrical impedance technique. Furthermore, we evaluated the predictive values of PBF and BMI for the cardiovascular risk factors.

\section{Material and Methods}

\section{Subjects}

All ambulatory adult subjects aged over 18 years who underwent a routine thorough health examination at the Chinese PLA General Hospital, Beijing, China, from February to September 2009 were enrolled. However, subjects with the following conditions were excluded: a history of acute coronary syndromes and/or cardiac infarction, any cardiac and renal dysfunction, a stroke history within the previous 6 months, a history of malignancy, severe hepatic disease, chronic consumptive diseases, anemia and severe malnutrition, pregnancy, and a history of hyperthyroidism and/ or hypothyroidism. In addition, those who were previously diagnosed and treated for hypertension, type II diabetes mellitus and dyslipidemia were also excluded from the study. The subjects who did not meet the exclusion criteria were informed of the research contents and enrolled in the study after they signed an informed consent form. Ethical approval for this study was provided by the Institutional Review Board of Chinese PLA General Hospital, Beijing, China (Chairman Prof. Kun-Lun He) on January 25, 2009.

\section{Measurement of body composition and categorizations of PBF and BMI}

Body composition was measured by appropriately trained medical care providers at the Health Examination Center of the Chinese PLA General Hospital. All subjects wore light clothing and stood in the upright position without shoes during the measurement. Height, waist circumference and hip circumference were measured to an accuracy of $0.1 \mathrm{~cm}$ and body weight to an accuracy of $0.1 \mathrm{~kg}$. BMI and waist-hip ratio (WHR) were calculated from the following two equations, respectively: BMI = body weight $/$ height $^{2}(\mathrm{~kg} /$ $\mathrm{m}^{2}$ ), and $\mathrm{WHR}=$ waist circumference/hip circumference $(\mathrm{cm} / \mathrm{cm})$. PBF was measured using the VIVENTE body composition analyzer (ARTEMIS, South Korea), which was approved by the State Food and DrugAdministration (SFDA) of China (Certificate No. 2210699). Measurements were conducted on the four limbs with an 8-electrode electrical impedance device using a 0.8-mA current at 5, 50, 250, and $500 \mathrm{kHz}$. Of the 8 electrodes, 4 were attached to the bilateral palms and thumbs, and the remaining electrodes were attached to the anterior and posterior soles bilaterally. Before measurement, all subjects underwent an overnight fast and were prohibited from vigorous activities within 12 $\mathrm{h}$ of measurement. The measurements were performed strictly according to manufacturer instructions. After gender, height and body weight input, body fat mass was determined using a proprietary bioelectrical impedance analyzing equation, which was not known to us. Thereafter, PBF was obtained from the following equation: body fat mass/ 
body weight x 100 .

Obesity was diagnosed if a subject had a BMI $\geq 25 \mathrm{~kg} /$ $\mathrm{m}^{2}$ (both male and female) or PBF $\geq 25 \%$ (male) or $\geq 30 \%$ (female) according to Asian BMI criteria (19) and the U.S. National Institutes of Health criterion standards for PBF (20). In addition, the subjects were further separated into four groups: group 1 (both normal $\mathrm{BMI}$ and PBF) = BMI $<25 \mathrm{~kg} / \mathrm{m}^{2}$ and PBF $<25 \%$ (male) or $<30 \%$ (female); group 2 (normal BMI, but abnormal PBF) $=\mathrm{BMI}<25 \mathrm{~kg} / \mathrm{m}^{2}$ and PBF $\geq 25 \%$ (male), or $\geq 30 \%$ (female); group 3 (abnormal BMI, but normal PBF) $=\mathrm{BMI} \geq 25 \mathrm{~kg} / \mathrm{m}^{2}$ and PBF $<25 \%$ (male), or $<30 \%$ (female), and group 4 (both abnormal $\mathrm{BMI}$ and $\mathrm{PBF}$ ) $=\mathrm{BMI} \geq 25 \mathrm{~kg} / \mathrm{m}^{2}$ and $\mathrm{PBF} \geq 25 \%$ (male), or $\geq 30 \%$ (female).

\section{Measurement and definition of cardiovascular risk factors}

After the subjects were seated and rested for $10 \mathrm{~min}$, systolic blood pressure (SBP) and diastolic blood pressure (DBP) were measured on the right arm using an electronic sphygmomanometer. Fasting blood samples were obtained in the early morning via the antecubital vein, preserved in a pre-chilled EDTA anticoagulation tube, and submitted to the Clinical Laboratory of PLA General Hospital for analysis. Fasting plasma glucose (FPG), total cholesterol (TC), triglyceride (TG), and high-density lipoprotein cholesterol (HDL-C) were determined using an Architect Ci8200-intergrated system (Abbott Laboratories, USA). Low-density lipoprotein cholesterol (LDL-C) concentration was calculated using the Friedewald equation (LDL-C $(\mathrm{mM})=\mathrm{TC}-[\mathrm{HDL}-\mathrm{C}+$ TG / 2.2]) (21). Then, cardiovascular risk factors including hypertension, hyperglycemia, and dyslipidemia were defined on the basis of the above listed variables in the present study (22).

In the present study, cardiovascular risk factors were defined as abnormal blood pressure and serum biochemical parameters such as lipids and glucose. The critical values of cardiovascular risk factors were designated as follows according to the 2009 American Diabetes Association Standards of Medical Care in Diabetes (23), the 2007 European Hypertension Guideline (22), and the 2007 Prevention and Treatment Guideline for Blood Lipid Abnormality in Chinese Adults (24): hypertension = SBP $\geq 130 \mathrm{mmHg}$ and/or DBP $\geq 85 \mathrm{mmHg}$; hyperglycemia = FPG $\geq 5.6 \mathrm{mM}(100 \mathrm{mg} / \mathrm{dL})$; dyslipidemia $=\mathrm{TC} \geq 5.18 \mathrm{mM}(200 \mathrm{mg} / \mathrm{dL})$, and $/$ or $\mathrm{TG} \geq 1.70$ $\mathrm{mM}$ (150 mg/dL) and/or LDL-C $\geq 3.37 \mathrm{mM} \mathrm{(130} \mathrm{mg/dL)} \mathrm{and/}$ or HDL-C $<1.04 \mathrm{mM}$ (40 mg/dL). In the present study, the criteria of the Prevention and Treatment Guideline for Blood Lipid Abnormality in Chinese Adults (24) were considered to be more suitable although the expert group from the National Cholesterol Education Program Adult Treatment Panel III (NCEP ATP III) (25) used different diagnostic criteria for dyslipidemia.

In addition, gender, age, lifestyle (including smoking, drinking and exercise), and family history of obesity were also considered as confounding risk factors in the present study. Smoking was defined as daily smoking of 10 or more cigarettes, cigars or pipes for at least 12 months at the time of the study (26). Drinking was defined as moderate to heavy alcohol consumption (an average of at least $15 \mathrm{~g} /$ day) at the time of the study. Exercise was defined as an average of at least moderate-intensity aerobic (endurance) physical activity for a minimum of 30 min on 5 days within a week (requiring $\geq 3$ metabolic equivalents an hour, including brisk walking) at the time of the study (27). A family history of obesity, type 2 diabetes, hypertension, stroke, and coronary heart disease was also included in the study.

\section{Statistical analysis}

Categorical variables were reported as frequency and percentages while numerical variables were reported as means \pm SD when they were normally distributed and as median and range if the data were abnormally distributed. The difference in numerical variables between two groups was analyzed using the Student $t$-test, and the difference between multiple groups was analyzed by analysis of variance (ANOVA), with post hoc multiple comparisons being performed using the Student-Newman-Keuls test. The chisquare test was used to analyze the differences in gender, age composition, lifestyle, family history, and cardiovascular risk factors among groups.

The odds ratio (OR) of cardiovascular risk factors in groups 2, 3, and 4, compared to group 1 (used as a reference) was analyzed by a multivariate logistic regression model where gender, age, lifestyle (including smoking, drinking and exercise), and BMI-PBF-based grouping were set as independent variables. Correlations of BMI and PBF with blood pressure, glucose and lipids were calculated using Pearson correlation analysis, and partial correlation analysis was used to adjust for gender, age, lifestyle, and family history. Several logistic regression models as well as the Poisson regression model were applied to determine if there was a difference in the OR of cardiovascular risk factors between BMI and PBF by setting different dependent and independent variables in the logistic regression analysis. All statistical analyses were conducted using the SPSS software (version 10; SPSS Inc., USA). A P value of $<0.05$ (two-tailed) was considered to be statistically significant.

\section{Results}

General characteristics and metabolic parameters of the study subjects in relation to the categorization by $B M I$ and PBF

A total of 3859 subjects (2173 males and 1686 females, age range: $18-85$ years) were eligible for the study. The percentage of the subjects included in groups 1, 2, 3, and 4 was $50.8,9.9,17.6$, and $21.7 \%$, respectively (Table 1 ). The numbers of males and females were similar in group 
Table 1. General characteristics and metabolic parameters of the study subjects in relation to the classification by body mass index (BMI) and percent body fat (PBF).

\begin{tabular}{|c|c|c|c|c|c|}
\hline Variables $(\mathrm{N}=3859)$ & $\begin{array}{c}\text { Group } 1 \text { [normal BMI/ } \\
\text { normal PBF }(\mathrm{N}=1961)]\end{array}$ & $\begin{array}{c}\text { Group } 2 \text { [normal BMI/ } \\
\text { abnormal PBF }(\mathrm{N}=381) \text { ] }\end{array}$ & $\begin{array}{c}\text { Group } 3 \text { [abnormal BMI/ } \\
\text { normal PBF }(\mathrm{N}=681) \text { ] }\end{array}$ & $\begin{array}{l}\text { Group } 4 \text { [abnormal BMI/ } \\
\text { abnormal PBF }(\mathrm{N}=836) \text { ] }\end{array}$ & $P$ value \\
\hline Gender & & & & & $<0.001$ \\
\hline Male & $996(50.8)$ & $62(16.3)$ & $611(89.7)$ & $504(60.3)$ & \\
\hline Female & $965(49.2)$ & $319(83.7)$ & $70(10.3)$ & 332 (39.7) & \\
\hline Age group & & & & & $<0.001$ \\
\hline Less than 30 years & $208(10.6)$ & $10(2.6)$ & $34(5.0)$ & $50(6.0)$ & \\
\hline $30-44$ years & $1092(55.7)$ & $173(45.4)$ & $382(56.1)$ & 391 (46.8) & \\
\hline $45-59$ years & $605(30.9)$ & $181(47.5)$ & $251(36.9)$ & 367 (43.9) & \\
\hline 60 years and above & $56(2.9)$ & $17(4.5)$ & $14(2.1)$ & $28(3.3)$ & \\
\hline \multicolumn{6}{|l|}{ Lifestyle } \\
\hline Smoking & $375(19.1)$ & $30(7.9)$ & $231(33.9)$ & 225 (26.9) & $<0.001$ \\
\hline Drinking & $251(12.8)$ & $25(6.6)$ & $137(20.1)$ & $119(14.2)$ & $<0.001$ \\
\hline Exercise & $564(28.8)$ & $103(27.0)$ & $210(30.8)$ & 245 (29.3) & 0.692 \\
\hline Family history & $225(11.5)$ & $51(13.4)$ & $84(12.3)$ & $107(12.8)$ & 0.629 \\
\hline Age (years) & $40.85 \pm 9.14^{\dagger}$ & $45.16 \pm 8.03 \pi$ & $42.66 \pm 7.85^{\ddagger}$ & $43.75 \pm 8.69 \S$ & $<0.001$ \\
\hline BMI $\left(\mathrm{kg} / \mathrm{m}^{2}\right)$ & $21.88 \pm 2.04^{\dagger}$ & $23.22 \pm 1.23^{\ddagger}$ & $26.46 \pm 1.25 \S$ & $27.94 \pm 2.18 \pi$ & $<0.001$ \\
\hline PB (\%) & $20.53 \pm 6.01^{\dagger}$ & $31.76 \pm 3.16 \pi$ & $22.31 \pm 3.05^{\ddagger}$ & $31.01 \pm 4.47 \S$ & $<0.001$ \\
\hline WHR & $0.81 \pm 0.05^{\dagger}$ & $0.85 \pm 0.03^{\ddagger}$ & $0.91 \pm 0.03 \S$ & $0.96 \pm 0.06 \pi$ & $<0.001$ \\
\hline $\mathrm{SBP}(\mathrm{mmHg})$ & $109.81 \pm 11.21 \dagger$ & $111.81 \pm 11.46^{\ddagger}$ & $116.52 \pm 9.77 \S$ & $118.07 \pm 10.00 \pi$ & $<0.001$ \\
\hline $\mathrm{DBP}(\mathrm{mmHg})$ & $72.04 \pm 8.05^{\dagger}$ & $73.23 \pm 7.72 \ddagger$ & $77.35 \pm 6.93 \S$ & $77.95 \pm 7.15 \S$ & $<0.001$ \\
\hline $\mathrm{FPG}(\mathrm{mM})$ & $5.34 \pm 0.43^{\dagger}$ & $5.42 \pm 0.45^{\ddagger}$ & $5.50 \pm 0.40 \S$ & $5.54 \pm 0.41 \S$ & $<0.001$ \\
\hline $\mathrm{TC}(\mathrm{mM})$ & $4.58 \pm 0.88^{\dagger}$ & $4.80 \pm 0.88^{\ddagger}$ & $4.84 \pm 0.85^{\ddagger} \S$ & $4.91 \pm 0.90 \S$ & $<0.001$ \\
\hline TG (mM) & $1.22 \pm 0.85^{\dagger}$ & $1.30 \pm 0.79^{\dagger}$ & $1.87 \pm 1.16 \S$ & $1.76 \pm 1.05^{\ddagger}$ & $<0.001$ \\
\hline HDL-C (mM) & $1.48 \pm 0.38 \S$ & $1.50 \pm 0.36 \S$ & $1.18 \pm 0.27^{\dagger}$ & $1.27 \pm 0.30 \ddagger$ & $<0.001$ \\
\hline LDL-C (mM) & $2.54 \pm 0.78^{\dagger}$ & $2.71 \pm 0.79 \ddagger$ & $2.80 \pm 0.82 \S$ & $2.85 \pm 0.81 \S$ & $<0.001$ \\
\hline
\end{tabular}

Data are reported as number with percent in parentheses or means \pm SD. $P$ values were obtained from comparisons among the four groups. The chi-square test was used to analyze categorical variables and ANOVA was used to analyze numerical variables. $†, \ddagger$, $\S$, and $\boldsymbol{\Psi}$ were derived from post hoc multiple comparisons (S-N-K). The level of significance was 0.05 . In a row, different symbols indicate statistically significant differences. Group 1 (both normal BMI and PBF): BMI $<25 \mathrm{~kg} / \mathrm{m}^{2}$ and PBF $<25 \%$ (male) or $<30 \%$ (female); group 2 (normal BMI but abnormal PBF): BMI $<25 \mathrm{~kg} / \mathrm{m}^{2}$ and PBF $\geq 25 \%$ (male) or $\geq 30 \%$ (female); group 3 (abnormal BMI but normal $\mathrm{PBF}$ ): $\mathrm{BMI} \geq 25 \mathrm{~kg} / \mathrm{m}^{2}$ and PBF $<25 \%$ (male) or $<30 \%$ (female); group 4 (both abnormal BMI and PBF): BMI $\geq 25 \mathrm{~kg} / \mathrm{m}^{2}$ and PBF $\geq 25 \%$ (male) or $\geq 30 \%$ (female). WHR = waist-hip ratio; SBP = systolic blood pressure; DBP = diastolic blood pressure; FPG = fasting plasma glucose; TC = total cholesterol; TG = triglyceride; HDL-C = high-density lipoprotein cholesterol; LDL-C = low-density lipoprotein cholesterol.

1 , whereas there were more females than males in group 2 $(83.7 \%)$ and more males than females in groups $3(89.7 \%)$ and $4(60.3 \%)$. Approximately $90 \%$ of subjects were aged $30-60$ years in the four groups. The proportions of smokers and drinkers were highest in group 3 and lowest in group 2. There appeared to be no difference in the proportion of subjects who exercised and with a family history of obesity, type 2 diabetes, hypertension, stroke, and coronary heart disease among the four groups.

The following body composition indices such as BMI, PBF and WHR and cardiovascular risk variables, such as age, SBP, DBP, FPG, TC, TG, HDL-C, and LDL-C are also shown in Table 1. There were significant differences in all variables among the four groups (all $\mathrm{P}<0.05$ ). Post hoc multiple comparison further showed that age and PBF were the highest in group 2. BMI, WHR, blood pressure, FPG,
TC, and LDL-C were the highest in group 4 and the lowest in group 1. Compared to group 3, HDL-C was higher, and the other risk factor variables (except TC) were lower in group 2 (Table 1).

\section{Cardiovascular risk factors of the study subjects}

A total of $2633(68.2 \%)$ of the 3859 study subjects were found to have one or more cardiovascular risk factors. The rates were $79.4 \%$ (1725/2173) in males and $53.9 \%$ $(908 / 1686)$ in females. The prevalence of hypertension, hyperglycemia, dyslipidemia, and two or more concomitant cardiovascular risk factors was higher in males than in females (all $P<0.001$; Figure 1).

The proportions of subjects with hypertension, hyperglycemia and dyslipidemia among subjects were 16.0 ( $\mathrm{N}=$ 618), $34.6(\mathrm{~N}=1334)$, and $49.5 \%(\mathrm{~N}=1910)$, respectively 
(Table 2). Whereas $41.1 \%(\mathrm{~N}=1585)$ of the subjects were found to have a single cardiovascular risk factor, $27.2 \%(\mathrm{~N}$ $=1048$ ) had two or more cardiovascular risk factors. The probability of having only one risk factor did not differ among groups. However, the probability of having two or more risk factors was significantly different among groups $(P<0.001)$, being the lowest (17.8\%) in group 1 and the highest (41.2\%) in group 4 (Table 2). The prevalence of hypertension, hyperglycemia and dyslipidemia was the lowest in group 1. The prevalence of hypertension and hyperglycemia was the highest in group 4, while the prevalence of dyslipidemia was the highest in group 3 (Table 2).

In the risk analysis, when group 1 (low BMI and PBF) was used as the reference, and gender, age and lifestyle (including smoking, drinking and exercise) were adjusted by logistic regression analysis, the risk for any of the cardiovascular risk factors in groups 2 (low BMI, but high PBF) and 4 (high $\mathrm{BMI}$ and $\mathrm{PBF}$ ) were $1.88(95 \% \mathrm{Cl}=1.45-2.45$, $\mathrm{P}<0.001)$ and $2.06(95 \% \mathrm{Cl}=1.26-3.35, \mathrm{P}=0.004)$ times those in group 1, respectively. No significant difference in cardiovascular risk factors was found between group 3 (high BMI, but low PBF) and group 1 (OR = 1.32, 95\% Cl $=0.92-1.89, \mathrm{P}=0.128 ;$ Figure 2).

\section{Correlations between BMI/PBF and blood pressure, glucose and lipid}

In order to further determine the difference in the evaluation of cardiovascular risk factors between BMI and PBF,

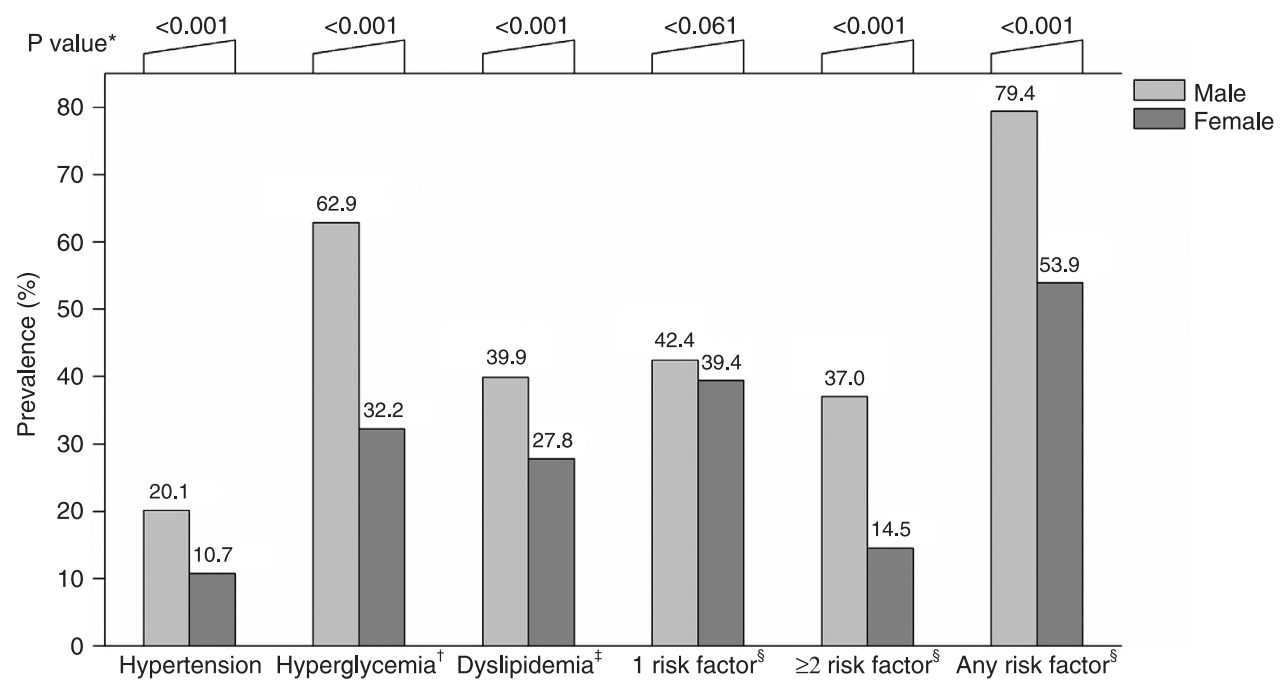

Figure 1. The prevalence of cardiovascular risk factors among males and females. *The $P$ value was obtained from the chi-square test. †Data were lost for 3 individuals. ‡Data were lost for 2 individuals. §Data of blood glucose and lipids were lost for 2 individuals. 1 risk factor = subjects with a single cardiovascular risk factor. $\geq 2$ risk factors $=$ subjects with two or more simultaneous cardiovascular risk factors. Any risk factor $=$ subjects with one or more simultaneous cardiovascular risk factors.

Table 2. Cardiovascular risk factors of the study subjects in relation to classification by body mass index and percent body fat.

\begin{tabular}{lcccrr}
\hline Variables & Group 1 $(\mathrm{N}=1961)$ & Group 2 $(\mathrm{N}=381)$ & Group 3 $(\mathrm{N}=681)$ & Group 4 (N=836) & P value \\
\hline Hypertension & $10.8(212 / 1961)$ & $11.8(45 / 381)$ & $20.6(140 / 681)$ & $26.4(221 / 836)$ & $<0.001$ \\
Hyperglycemia $^{\dagger}$ & $28.3(554 / 1960)$ & $35.4(135 / 381)$ & $41.7(284 / 681)$ & $43.3(361 / 834)$ & $<0.001$ \\
Dyslipidemia $^{\ddagger}$ & $38.2(749 / 1960)$ & $46.2(176 / 381)$ & $66.2(451 / 681)$ & $64.0(534 / 835)$ & $<0.001$ \\
1 risk factor\$ & $39.3(771 / 1960)$ & $45.4(173 / 381)$ & $42.6(290 / 681)$ & $42.0(351 / 835)$ & 0.094 \\
$\geq 2$ risk factors & $17.8(348 / 1960)$ & $22.3(85 / 381)$ & $39.8(271 / 681)$ & $41.2(344 / 835)$ & $<0.001$ \\
Any risk factorll & $57.1(1119 / 1960)$ & $67.7(258 / 381)$ & $82.4(561 / 681)$ & $83.2(695 / 835)$ & $<0.001$ \\
\hline
\end{tabular}

Groups 1-4 are identified in Table 1. Data are reported as percent (number of abnormal subjects/number of subjects in group $\times 100$ ). The $P$ value was obtained from the chi-square test. tData for 3 individuals were lost. ‡Data for 2 individuals were lost. §Subjects with a single cardiovascular risk factor. ISubjects with two or more cardiovascular risk factors simultaneously. ISubjects with one or more cardiovascular risk factors simultaneously. §, I, IIData of blood glucose and lipids were lost for 2 individuals. 
correlations between BMI/PBF and major cardiovascular risk variables including blood pressure, glucose and lipids were first analyzed. We found that BMI was negatively correlated with HDL-C while PBF showed no correlation with HDL-C. Both BMI and PBF were positively correlated with the other variables (Table 3).

After other confounding factors such as age, gender, lifestyle, and family history were adjusted by partial correlation analysis, BMI was found to be positively correlated with SBP and DBP, and negatively correlated with HDL-C; however, it showed no correlations with TC, TG, LDL-C, or FPG. On the other hand, PBF was positively correlated with TG, TC, LDL-C, and FPG, and negatively correlated with HDL-C, although it showed no correlations with SBP and DBP (Table 3).

\section{Logistic regression of independent factors associated with cardiovas- cular risk factors}

We further carried out a logistic regression analysis using one or more risk factors as dependent variables, with the absence of any of the three cardiovascular risk factors set as 0 and the presence of one or more risk factors of the three cardiovascular risk factors as 1 . The confounding factors such as gender, age, WHR, BMI, PBF, smoking, drinking, exercise, and family history were treated as independent variables. BMI*PBF was also included in the logistic regression analysis in order to determine whether there was an interaction between BMI and PBF in terms of association with cardiovascular risk factors, and the effect of PBF on the association of BMI with cardiovascular risk factors.

Cardiovascular risk factors were not associated with BMI (OR $=1.01$, $95 \% \mathrm{Cl}=0.91-1.12, \mathrm{P}=0.870)$, but were correlated with gender, age, PBF, and smoking, as the OR of cardiovascular risk factors about PBF was $1.04(95 \% \mathrm{Cl}$ $=1.00-1.07, \mathrm{P}=0.028)$. Moreover, no interaction was found between the BMI and PBF association with cardiovascular risk factors $(\mathrm{OR}=1.00,95 \% \mathrm{Cl}=0.90$ $1.13, P=0.955)$ (Table 4). Poisson regression analysis also revealed that cardiovascular risk factors were associated

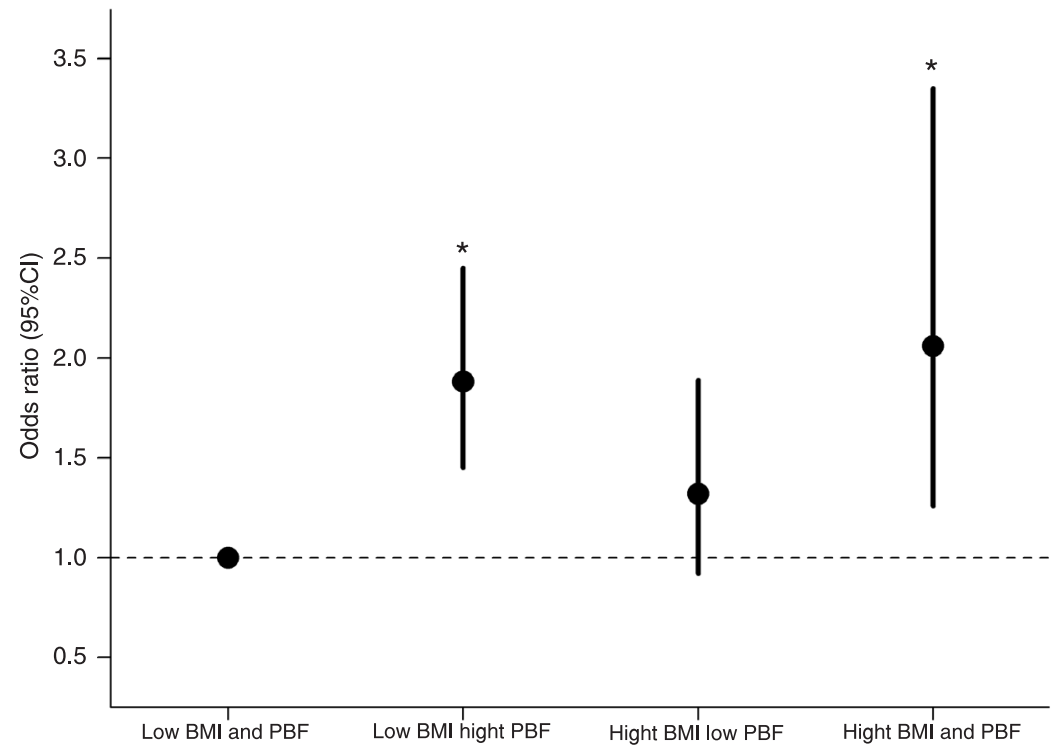

Figure 2. Risks for any of the cardiovascular risk factors according to subject groups classified by body mass index (BMI) and percent body fat (PBF). ${ }^{*} \mathrm{P}<0.01$; gender, age, and lifestyle (including smoking, drinking and exercise) were adjusted by the logistic regression analysis (Wald test). Low BMI and PBF was set as a reference. Low BMI and PBF = BMl $<25 \mathrm{~kg} / \mathrm{m}^{2}$, and PBF $<25 \%$ (male) or $<30 \%$ (female); low $\mathrm{BMl}$ and high PBF = BMI $<25 \mathrm{~kg} / \mathrm{m}^{2}$, and PBF $\geq 25 \%$ (male) or $\geq 30 \%$ (female); high $\mathrm{BMI}$ and low PBF $=\mathrm{BMI} \geq 25 \mathrm{~kg} / \mathrm{m}^{2}$ and $\mathrm{PBF}<25 \%$ (male) or $<30 \%$ (female); high BMI and $\mathrm{PBF}=\mathrm{BMI} \geq 25 \mathrm{~kg} / \mathrm{m}^{2}$ and $\mathrm{PBF} \geq 25 \%$ (male) or $\geq 30 \%$ (female). $95 \% \mathrm{Cl}=95 \%$ confidence interval.

Table 3. Correlations between body mass index/percent body fat and blood pressure, glucose and lipids.

\begin{tabular}{lcccccc}
\hline & \multicolumn{2}{c}{ Body mass index } & & \multicolumn{2}{c}{ Percent body fat } \\
\cline { 2 - 3 } \cline { 5 - 6 } & $\begin{array}{c}\text { Correlation } \\
\text { coefficient }\end{array}$ & $\begin{array}{c}\text { Partial correlation } \\
\text { coefficient }\end{array}$ & & $\begin{array}{c}\text { Correlation } \\
\text { coefficient }\end{array}$ & $\begin{array}{c}\text { Partial correlation } \\
\text { coefficient }\end{array}$ \\
\hline SBP $(\mathrm{mmHg})$ & $0.403^{\dagger}$ & $0.071^{\dagger}$ & & $0.098^{\dagger}$ & -0.006 \\
$\mathrm{DBP}(\mathrm{mmHg})$ & $0.409^{\dagger}$ & $0.054^{\dagger}$ & & $0.075^{\dagger}$ & 0.008 \\
$\mathrm{FPG}(\mathrm{mM})$ & $0.249^{\dagger}$ & 0.02 & & $0.088^{\dagger}$ & $0.038^{\star}$ \\
$\mathrm{TC}(\mathrm{mM})$ & $0.169^{\dagger}$ & -0.019 & & $0.112^{\dagger}$ & $0.078^{\dagger}$ \\
TG $(\mathrm{mM})$ & $0.350^{\dagger}$ & -0.021 & & $0.049^{\dagger}$ & $0.051^{\dagger}$ \\
$\mathrm{HDL}-\mathrm{C}(\mathrm{mM})$ & $-0.432^{\dagger}$ & $-0.063^{\dagger}$ & & -0.003 & $-0.050^{\dagger}$ \\
LDL-C (mM) & $0.189^{\dagger}$ & 0.016 & & $0.097^{\dagger}$ & $0.079^{\dagger}$ \\
\hline
\end{tabular}

$P$ values were obtained from Pearson correlation analysis and partial correlation analysis. ${ }^{*} \mathrm{P}<0.05$ and ${ }^{\dagger} \mathrm{P}<0.01$ ( $t$-test). Confounding factors such as age, gender, lifestyle, and family history were adjusted in the partial correlation analysis. SBP = systolic blood pressure; $\mathrm{DBP}=$ diastolic blood pressure; FPG = fasting plasma glucose; $\mathrm{TC}=$ total cholesterol; $\mathrm{TG}$ = triglyceride; $\mathrm{HDL}-\mathrm{C}=$ high-density lipoprotein cholesterol; LDL-C = low-density lipoprotein cholesterol.

with PBF rather than BMI (Supplementary Table S1).

Furthermore, when the probability of having hypertension, dyslipidemia, or hyperglycemia was set as a dependent 
variable separately, PBF was able to predict the probability of hypertension $(\mathrm{OR}=1.03,95 \% \mathrm{Cl}=1.01-1.04, \mathrm{P}=0.001)$, dyslipidemia $(\mathrm{OR}=1.05,95 \% \mathrm{Cl}=1.02-1.09, \mathrm{P}=0.001)$ and hyperglycemia $(\mathrm{OR}=1.03,95 \% \mathrm{Cl}=1.00-1.07, \mathrm{P}=$ 0.038 ), whereas BMI failed to predict the probability of hypertension $(\mathrm{OR}=1.09,95 \% \mathrm{Cl}=0.99-1.20, \mathrm{P}=0.076)$, dyslipidemia $(\mathrm{OR}=0.97,95 \% \mathrm{Cl}=0.87-1.07, \mathrm{P}=0.511)$ and hyperglycemia $(\mathrm{OR}=1.09,95 \% \mathrm{Cl}=0.99-1.20, \mathrm{P}=$ 0.083) (Table 4).

\section{Discussion}

BMI and PBF are both used clinically to identify the presence of obesity in individuals. However, persons with a normal BMI but a high PBF, or a high BMI but a normal PBF can be identified when both parameters are used. In the present study, more than one quarter $(27.5 \%)$ of the 3859 subjects fell into normal BMI and high PBF or high BMI and normal PBF. We showed that individuals with a normal BMI but a high PBF exhibited a cardiovascular risk profile similar to that of those with a high BMI and a high PBF, whereas individuals with a high BMI but a normal PBF showed a cardiovascular risk profile similar to that of those with a normal BMI and a normal PBF (Figure 2). Moreover, partial correlation analysis revealed that PBF was more closely correlated with blood pressure, glucose and lipids than BMI (Table 3), and logistic regression analysis also revealed that PBF, rather than BMI, was independently associated with cardiovascular risk factors (Table 4). These findings indicate that PBF should be a better predictor of cardiovascular risk factors than BMI among these subjects.

The present study also demonstrated that females predominated $(83.7 \%$ ) in group 2 (high PBF but normal $\mathrm{BMI}$ ) and males predominated (89.7\%) in group 3 (high BMI but normal PBF; Table 1). This finding agrees with previous observations that more females have a high PBF but normal $\mathrm{BMI}$ and more males have a high BMI but normal $\operatorname{PBF}(7,10,15)$. Our data also indicate that the prevalence of cardiovascular risk factors was higher in males than in females (Figure 1). Since males dominated in group 3 (high BMI but normal PBF), it is not a surprise that the overall prevalence of cardiovascular risk factors in group 3 (high BMI but normal PBF) was higher than in group 2 (Table 2). Since age and lifestyle may also influence the comparison, the results of cardiovascular risk factors among the four groups $(28,29)$, gender, age, and lifestyle were adjusted in the logistic regression analysis, which showed that the cardiovascular risk was relatively higher in group 2 (low BMI, but high PBF) than in group 3 (high BMI, but low PBF) when group 1 (low BMI and PBF) was used as a reference (Figure 2 ).

$\mathrm{BMI}$ is only an indirect measure of body fat mass and thus may not accurately reflect cardiovascular risks and human metabolic disorders (30). Wang et al. (31) investigated 4907 Chinese subjects and found that BMI had limited in-
Table 4. Logistic regression analysis of variables independently associated with cardiovascular risk factors.

\begin{tabular}{|c|c|c|c|}
\hline Model & $\chi^{2}$ value & $P$ value & Odds ratio $(95 \% \mathrm{Cl})$ \\
\hline \multicolumn{4}{|l|}{ Model $1 \dagger$} \\
\hline BMI $\left(\mathrm{kg} / \mathrm{m}^{2}\right)$ & 0.027 & 0.870 & $1.01(0.91-1.12)$ \\
\hline PBF (\%) & 4.850 & 0.028 & $1.04(1.00-1.07)$ \\
\hline BMI*PBF & 0.003 & 0.955 & $1.00(0.90-1.13)$ \\
\hline \multicolumn{4}{|l|}{ Model $2 \ddagger$} \\
\hline BMI $\left(k g / m^{2}\right)$ & 3.140 & 0.076 & $1.09(0.99-1.20)$ \\
\hline PBF (\%) & 10.862 & 0.001 & $1.03(1.01-1.04)$ \\
\hline BMI*PBF & 0.103 & 0.748 & $0.98(0.89-1.09)$ \\
\hline \multicolumn{4}{|l|}{ Model $3 \S$} \\
\hline BMI $\left(k g / m^{2}\right)$ & 0.433 & 0.511 & $0.97(0.87-1.07)$ \\
\hline PBF (\%) & 10.147 & 0.001 & 1.05 (1.02-1.09) \\
\hline $\mathrm{BMI}^{*} \mathrm{PBF}$ & 1.136 & 0.287 & $0.95(0.85-1.05)$ \\
\hline \multicolumn{4}{|l|}{ Model 4ा } \\
\hline BMI $\left(\mathrm{kg} / \mathrm{m}^{2}\right)$ & 3.008 & 0.083 & $1.09(0.99-1.20)$ \\
\hline PBF (\%) & 4.305 & 0.038 & $1.03(1.00-1.07)$ \\
\hline $\mathrm{BMI}^{*} \mathrm{PBF}$ & 0.119 & 0.730 & $0.98(0.89-1.09)$ \\
\hline
\end{tabular}

The inclusion criterion for variables was 0.05 and the exclusion criterion was 0.10 . TThe probability of having one or more risk factors was set as a dependent variable, and the confounding factors such as gender, age, waist-hip ratio (WHR), body mass index (BMI), percent body fat (PBF), BMI*PBF, smoking, drinking, exercise, and family history were set as independent variables. $B M{ }^{\star} \mathrm{PBF}$ represented the interaction between PBF and BMI in terms of association with cardiovascular risk factors. \$The probability of having hypertension was set as a dependent variable, and gender, age, WHR, BMI, PBF, BMI*PBF, smoking, drinking, exercise, family history, dyslipidemia, and hyperglycemia were set as independent variables. §The probability of having dyslipidemia was set as a dependent variable, and gender, age, WHR, BMI, PBF, BMI*PBF, smoking, drinking, exercise, family history, hypertension and hyperglycemia were set as independent variables. IThe probability of having hyperglycemia was set as a dependent variable, and gender, age, WHR, BMI, PBF, BMI*PBF, smoking, drinking, exercise, family history, hypertension, and dyslipidemia were set as independent variables. $95 \% \mathrm{Cl}=95 \%$ confidence interval.

terpreting power for subjects with BMI in the mid-range (24 and $27.9 \mathrm{~kg} / \mathrm{m}^{2}$ ) although it correlated very well with PBF. $\mathrm{PBF}$, on the other hand, reflects body composition and is directly correlated with cardiovascular risks $(12,13,32)$. We previously demonstrated that PBF better reflected cardiac function and arterial compliance than BMI (18).

In the present study, we showed that, although BMI was correlated with blood pressure, glucose and lipid in univariate correlation analysis, the correlation disappeared when confounding factors such as age, gender, lifestyle, and family history were adjusted (Table 3) and logistic regression analysis further demonstrated that BMI was not associated with cardiovascular risk factors (Table 4). PBF, on the other hand, was well correlated with cardiovascular 
risk factors even when confounding factors were considered (Table 3). We found that increased PBF was associated with increased cardiovascular risk factors (Table 4). Indeed, Romero-Corral et al. and others $(33,34)$ reported that individuals with a high body fat content but a normal BMI (i.e., normal weight obesity) were more predisposed to type II diabetes mellitus and cardiovascular disease.

Individuals routinely practicing vigorous exercise would be considered overweight or obese when assessed by BMI but they may be considered normal if assessed by PBF. The excessive body weight in these muscular individuals who have a normal fat mass does not influence their cardiovascular risks. For example, Segal et al. (35) reported that the cardiovascular risk of males with a normal PBF but a high BMI was comparable to that of males with normal PBF and BMI. Oreopoulos et al. (32) studied 140 patients with cardiac failure and found that those with a high lean mass had a longer survival. In the present study, we also showed that individuals with a high BMI but a normal PBF did not exhibit an appreciably enhanced cardiovascular risk compared to those with a normal body weight after gender, age and lifestyle were adjusted (Figure 2).

Several limitations of the present study should be recognized. The application of the bioelectrical impedance method for the determination of PBF has been reported to be less accurate than underwater weighing, dual-energy $X$-ray absorptiometry or air replacement plethysmography (36), and its validity has been doubted for use in large epidemiological studies (37). However, due to its efficiency, feasibility and safety, the method is being still widely applied in various recent studies for the measurement of body composition, estimation of visceral fat area, assessment of certain diseases such as liver steatosis and local arterial stiffness, and prediction of cell viability during ischemia and reperfusion in rat liver (38-40). In a previous study, we also used this technique to study the correlation of body composition and cardiac function in 325 healthy subjects (18). In the present study, we used the same method to study 3859 subjects and, consistent with our previous study, we found that PBF would probably be a better predictor than BMI of cardiovascular risk factors in the study subjects. It should be

\section{References}

1. Ogden CL, Yanovski SZ, Carroll MD, Flegal KM. The epidemiology of obesity. Gastroenterology 2007; 132: 20872102.

2. Flegal KM, Graubard BI, Williamson DF, Gail MH. Excess deaths associated with underweight, overweight, and obesity. JAMA 2005; 293: 1861-1867.

3. Jia WP, Wang C, Jiang S, Pan JM. Characteristics of obesity and its related disorders in China. Biomed Environ Sci 2010; 23: 4-11.

4. Stewart ST, Cutler DM, Rosen AB. Forecasting the effects of obesity and smoking on U.S. life expectancy. N Engl J Med kept in mind that some kinds of variance such as race and medical conditions would be expected at the individual level, which might impact the PBF measurement by bioelectrical impedance analysis, and thus the subsequent outcome of the relationship between PBF and cardiovascular risk factors. However, in the present study, all subjects were of the Han nationality, and certain diseases were excluded, and thus the results obtained here were less influenced by race and underlying medical conditions. In addition, there was no widely accepted standard criterion or cutoff of PBF for defining overweight or obesity by the PBF method. In the present study, we used the cutoff of PBF $\geq 25 \%$ (male) or $\geq 30 \%$ (female) to define abnormal fat using the National Institutes of Health criteria for PBF, which does state that "Most health care providers agree that men with more than 25 percent body fat and women with more than 30 percent body fat are considered obese" (20).

In conclusion, after adjustment of confounding factors such as age, gender, lifestyle, and family history, BMI is positively correlated with SBP and DBP, and negatively correlated with HDL-C, but lacks any correlations with TC, TG, LDL-C, and FPG, whereas PBF is positively correlated with TG, TC, LDL-C, and FPG, and negatively correlated with HDL-C. Moreover, logistic regression analysis reveals that PBF, and not BMI, is independently associated with cardiovascular risk factors. Therefore, in clinical practice, we should pay more attention to the measurement of body composition and PBF, in an attempt to predict cardiovascular risk factors, particularly when BMI and PBF contradict each other in Chinese people.

\section{Acknowledgments}

The authors gratefully acknowledge the skillful assistance of the doctors and staff of the International Medical Center in the Chinese PLA General Hospital for technical help with measurements of body composition. We thank Medjaden Bioscience Limited for assisting with the preparation of the manuscript. Research supported in part by the National Natural Science Foundation of China (\#30570738; http://www.nsfc.gov.cn/Portal0/default124.htm).
2009; 361: 2252-2260.

5. Steinberger J, Kelly AS. Cardiovascular risk at the extremes of body composition. J Pediatr 2006; 149: 739-740.

6. Whitlock G, Lewington S, Sherliker P, Clarke R, Emberson $\mathrm{J}$, Halsey $\mathrm{J}$, et al. Body-mass index and cause-specific mortality in 900,000 adults: collaborative analyses of 57 prospective studies. Lancet 2009; 373: 1083-1096.

7. Romero-Corral A, Somers VK, Sierra-Johnson J, Thomas $\mathrm{RJ}$, Collazo-Clavell ML, Korinek J, et al. Accuracy of body mass index in diagnosing obesity in the adult general population. Int J Obes 2008; 32: 959-966. 
8. Jackson AS, Ellis KJ, McFarlin BK, Sailors MH, Bray MS. Body mass index bias in defining obesity of diverse young adults: the Training Intervention and Genetics of Exercise Response (TIGER) study. Br J Nutr 2009; 102: 1084-1090.

9. Okorodudu DO, Jumean MF, Montori VM, Romero-Corral A, Somers VK, Erwin PJ, et al. Diagnostic performance of body mass index to identify obesity as defined by body adiposity: a systematic review and meta-analysis. Int J Obes 2010; 34: 791-799.

10. Who Expert Consultation. Appropriate body-mass index for Asian populations and its implications for policy and intervention strategies. Lancet 2004; 363: 157-163.

11. Low S, Chin MC, Ma S, Heng D, Durenberg-Yap M. Rationale for redefining obesity in Asians. Ann Acad Med Singapore 2009; 38: 66-69.

12. Imamura $\mathrm{Y}$, Uto $\mathrm{H}$, Oketani $\mathrm{M}$, Hiramine $\mathrm{Y}$, Hosoyamada $\mathrm{K}$, Sho Y, et al. Association between changes in body composition and the increasing prevalence of fatty liver in Japanese men. Hepatol Res 2008; 38: 1083-1086.

13. Bandyopadhyay A. Anthropometry and body composition in soccer and volleyball players in West Bengal, India. $J$ Physiol Anthropol 2007; 26: 501-505.

14. Akay AF, Gedik A, Tutus A, Sahin H, Bircan MK. Body mass index, body fat percentage, and the effect of body fat mass on SWL success. Int Urol Nephrol 2007; 39: 727-730.

15. Meeuwsen S, Horgan GW, Elia M. The relationship between $\mathrm{BMI}$ and percent body fat, measured by bioelectrical impedance, in a large adult sample is curvilinear and influenced by age and sex. Clin Nutr 2010; 29: 560-566.

16. Adams TD, Heath EM, Lamonte MJ, Gress RE, Pendleton R, Strong $\mathrm{M}$, et al. The relationship between body mass index and percent body fat in the severely obese. Diabetes Obes Metab 2007; 9: 498-505.

17. Sun G, French CR, Martin GR, Younghusband B, Green RC, Xie YG, et al. Comparison of multifrequency bioelectrical impedance analysis with dual-energy $\mathrm{X}$-ray absorptiometry for assessment of percentage body fat in a large, healthy population. Am J Clin Nutr 2005; 81: 74-78.

18. Zeng Q, Sun XN, Fan L, Ye P. Correlation of body composition with cardiac function and arterial compliance. Clin Exp Pharmacol Physiol 2008; 35: 78-82.

19. Wen CP, David Cheng TY, Tsai SP, Chan HT, Hsu HL, Hsu $\mathrm{CC}$, et al. Are Asians at greater mortality risks for being overweight than Caucasians? Redefining obesity for Asians. Public Health Nutr 2009; 12: 497-506.

20. US Department of Health and Human Services, National Institutes of Health. WIN Weight Control Network. Understanding Adult Obesity. NIH Publication No. 01-3680. http:// win.niddk.nih.gov/publications/PDFs/adultobesbw1201.pdf. Accessed October 14, 2001

21. Friedewald WT, Levy RI, Fredrickson DS. Estimation of the concentration of low-density lipoprotein cholesterol in plasma, without use of the preparative ultracentrifuge. Clin Chem 1972; 18: 499-502.

22. Mancia G, De Backer G, DominiczakA, Cifkova R, Fagard R, Germano G, et al. 2007 Guidelines for the Management of Arterial Hypertension: The Task Force for the Management of Arterial Hypertension of the European Society of Hypertension (ESH) and of the European Society of Cardiology (ESC). J Hypertens 2007; 25: 1105-1187.

23. American Diabetes Association. Standards of medical care in diabetes - 2009. Diabetes Care 2009; 32 (Suppl 1): S13-
S61.

24. United Committee for Compilation of Prevention and Treatment Guideline for Blood Lipid Abnormality in Chinese Adults. Prevention and treatment guideline for blood lipid abnormality in Chinese adults. Chinese J Cardiol 2007; 35: 390-419.

25. Executive Summary of the Third Report of the National Cholesterol Education Program (NCEP). Expert panel on detection, evaluation, and treatment of high blood cholesterol in adults (adult treatment panel III). JAMA 2001; 285: 2486-2497.

26. Liu T, Wang H, Qiu Q, Tan LL, Chen W, Yu XQ, et al. [Mediation of abdominal obesity on the association between cigarette smoking and beta-cell function]. Zhonghua Liu Xing Bing Xue Za Zhi 2010; 31: 988-991.

27. Haskell WL, Lee IM, Pate RR, Powell KE, Blair SN, Franklin $\mathrm{BA}$, et al. Physical activity and public health: updated recommendation for adults from the American College of Sports Medicine and the American Heart Association. Med Sci Sports Exerc 2007; 39: 1423-1434.

28. Vyssoulis GP, Karpanou EA, Liakos Cl, Kyvelou SM, Tzamou VE, Michaelides AP, et al. Cardiovascular risk factor(s) prevalence in Greek hypertensives. Effect of gender and age. J Hum Hypertens 2011 [Epub ahead of print].

29. Wijndaele K, Brage S, Besson H, Khaw KT, Sharp SJ, Luben $\mathrm{R}$, et al. Television viewing and incident cardiovascular disease: prospective associations and mediation analysis in the EPIC Norfolk Study. PLoS One 2011; 6: e20058.

30. Palaniappan LP, Wong EC, Shin JJ, Fortmann SP, Lauderdale DS. Asian Americans have greater prevalence of metabolic syndrome despite lower body mass index. Int $\mathrm{J}$ Obes 2011; 35: 393-400.

31. Wang C, Hou XH, Zhang ML, Bao YQ, Zou YH, Zhong WH, et al. Comparison of body mass index with body fat percentage in the evaluation of obesity in Chinese. Biomed Environ Sci 2010; 23: 173-179.

32. Oreopoulos A, Ezekowitz JA, McAlister FA, Kalantar-Zadeh $\mathrm{K}$, Fonarow GC, Norris CM, et al. Association between direct measures of body composition and prognostic factors in chronic heart failure. Mayo Clin Proc 2010; 85: 609-617.

33. Romero-Corral A, Somers VK, Sierra-Johnson J, Korenfeld Y, Boarin S, Korinek J, et al. Normal weight obesity: a risk factor for cardiometabolic dysregulation and cardiovascular mortality. Eur Heart J 2010; 31: 737-746.

34. Cho YG, Song HJ, Kim JM, Park KH, Paek YJ, Cho JJ, et al. The estimation of cardiovascular risk factors by body mass index and body fat percentage in Korean male adults. Metabolism 2009; 58: 765-771.

35. Segal KR, Dunaif A, Gutin B, Albu J, Nyman A, Pi-Sunyer FX. Body composition, not body weight, is related to cardiovascular disease risk factors and sex hormone levels in men. $J$ Clin Invest 1987; 80: 1050-1055.

36. Jebb SA, Elia M. Techniques for the measurement of body composition: a practical guide. Int J Obes Relat Metab Disord 1993; 17: 611-621.

37. Dehghan M, Merchant AT. Is bioelectrical impedance accurate for use in large epidemiological studies? Nutr J 2008; 7: 26 .

38. Minematsu K, Kaneko Y, Nakazato M, Maeda T, Maeda T, Christopher NJ, et al. Percentage body fat assessed by bioelectrical impedance analysis as a new health index for rural areas in the Asia-Pacific region. Acta Med Nagasakiensia 
2009; 54: 39-44.

39. Nagai M, Komiya H, Mori $\mathrm{Y}$, Ohta T, Kasahara $\mathrm{Y}$, Ikeda $\mathrm{Y}$. Estimating visceral fat area by multifrequency bioelectrical impedance. Diabetes Care 2010; 33: 1077-1079.
40. Bhati CS, Silva MA, Wigmore SJ, Bramhall SR, Mayer DA, Buckels JA, et al. Use of bioelectrical impedance analysis to assess liver steatosis. Transplant Proc 2009; 41: 16771681. 